\title{
DISTRIBUTION OF IMPACT INDUCED PRESSURES AT THE FACE OF UNIFORMLY SLOPED SEA DIKES: PRELIMINARY 2D EXPERIMENTAL RESULTS
}

\begin{abstract}
Stagonas D. ${ }^{1}$ Muller G. ${ }^{2}$ Ramachandran K. ${ }^{3}$ Schimmels S. ${ }^{3}$ and Dane A. ${ }^{2}$
Although existing knowledge on the vertical distribution of impact pressures on sea-dikes is well established only very little is known with respect to their horizontal distribution. A collaboration developed between the University of Southampton, Uk and FZK, Hannover looks in more detail at the distribution of pressures induced by waves breaking on the face of a sea-dike. For this, 2D large scale experiments with waves breaking on a 1:3 sea dike were conducted but instead of pressure transducers a tactile pressure sensor was used to map the impact pressures. Such sensors were initially used with breaking waves in the University of Southampton and their use for large scale experiments was attempted here for the first time. In the current paper the calibration and application of the tactile sensor for experiments involving up to $1 \mathrm{~m}$ high and $8 \mathrm{sec}$ long waves are initially described. Preliminary results illustrating the simultaneous distribution of impact induced pressures over an area of $426.7 \times 487.7 \mathrm{~mm}$ are then presented. Based on these pressure maps the vertical and horizontal location of maximum breaking wave induced pressures is also deduced.
\end{abstract}

Keywords: impact induced pressure distribution; sea dikes

\section{Introduction}

Sea dikes are onshore sloped sea structures aiming to prevent flooding of low lying coastal areas and protect vital pieces of industrial and urban infrastructure such as LNG terminals. For countries like the Netherlands, Denmark and Germany sea dikes form a large part of the existing coastal defenses and a significant investment is required for their maintenance on an annual base. In the same time, the impact of waves breaking on the seaward face of such structures has been reported as one of the main causes of initial sea dike failure.

Previously a large number of experimental investigations was focused on the study of the effects of breaking waves at the seaward face of sea dikes. Empirical formulae for the prediction of impact induced pressures have been developed to aid on the design of sea dikes and scientific knowledge has been greatly enhanced.

As an example, the occurrence of maximum pressures $\left(\mathrm{P}_{\max }\right)$ bellow still water level (SWL) is by now well documented. However, information on the horizontal distribution of impact pressures is scarce. The current work follows a different approach which does not involve the use of pressure transducers. A commercially available pressure mapping system was adjusted for use in large scale experiments involving breaking waves. The system used for the large scale experiments presented here allows for the instantaneous measurement of pressure / force acting on 2016 points spread over an area of $426.7 \times 487.7 \mathrm{~mm}$. Previous experience at the University of Southampton involved the use of a similar system, with a smaller however measuring area, for the mapping of wave impact induced pressures at vertical sea walls and uniformly sloped sea dikes in small scale wave flume. Following a brief review of the existing literature the calibration and application of the system is described in the methods section. Preliminary experimental results are accordingly presented in support of the conclusions reported at the end of the current paper.

\section{Literature review}

Sea dikes are onshore sloped sea structures designed to protect low lying areas of coastal flood plains from being intermittently or regularly flooded by coastal waters (Burcharth and Hughes, 2005). Typical cross-sections include a shallow seaward slope of 1:3 to 1:5 and a steeper landward slope of 1:2 to 1:4 in order to reduce space requirement. A sand core is typically used to construct the main body of the sea dike, although the use of clay is also possible. Clay is, however, typically applied next due to its provision of resistance against erosion. Finally a cover layer is applied to reinforce the resistance offered by the clay. For the latter the use of a layer of grass is an attractive option but concrete slabs, clay and stones are also used, (Stanczak, 2008).

Nonetheless, sea dikes can fail their purpose under the continuous wave action. The most important failure modes involve breaching during storm surges, wave overtopping and failure of the seaward slope. One major failure mechanism contributing to the latter failure mode refers to the

${ }^{1}$ Civil, Environmental and Geomatic Engineering, University College London, Chadwick Building, Gower Street, London, WC1E 6BT, UK

${ }^{2}$ Civil, Maritime and Environmental Engineering and Energy Unit, University of Southampton, Highfield campus, Southampton, SO17 1BJ, UK

${ }^{3}$ Forschungszentrum Küste (FZK), Leibniz UniversitatLaboratory, Merkurstrasse 11, Hannover, 30419, Germany 
pressure/loads generated under breaking waves. Pressure analysis on sloped coastal defences is by no means a new phenomenon with more than 140 years' worth of data (Grune, 1988).

Plunging breakers have been reported to be responsible for the highest peak pressures occurring at the face of sea dikes (Marth et al., 2005). Based on numerous single point field and experimental measurements the pressure time-history trend has been extensively researched, (e.g. Grune, 1988 \& 1992 and Fuhrboter and Sparboom, 1988). Upon breaking impact induced pressures / forces are developed at the point of impingement resulting on highly localised loads. Pressure waves propagate within existing/generated gaps leading to pressure amplification or dumping; see also (Recio and Oumeraci, 2009).

With reference to SWL, the vertical location of impact pressure maxima has been reported to range from $+0.5 \mathrm{Hs}$ to $-1.8 \mathrm{Hs}$. Overall 5 different loading zones at the vertical face of sea dikes have been recognised in order to identify failure areas and aid on the design, construction and maintenance of the structure. More detail, small and larger scale, experimental studies (Breteler, 2007) on the vertical distribution of pressure linked the width of the affected area to the incoming wave height and the surf similarity parameter.

In summary, nearly all experimental studies looking at the pressure magnitude on sea dikes an arrangement of pressure transducers has been located along the centreline of the structure. Delft (TAW, 1984) placed 35 pressure transducers on a 1:6 slope sea dike in the Delta Flume, Netherlands. 10 of these transducers were located in the horizontal direction, unfortunately this data was not fully analysed and no results were published (Davidse, 2009). Hence, and to the best of the authors' knowledge, existing knowledge on the horizontal coherence of impact induced pressures is limited.

\section{Methods}

\section{The experimental arrangement}

For all experiments reported in the current work regular waves were used. Although initial experiments were conducted in the University of Southampton small scale wave flume, $12 \times 0.45 \times 0.45 \mathrm{~m}$, all results presented here refer to the large scale experiments conducted at Forschungszentrum Küste (FZK), Hannover. The wave flume at FZK measures $307 \mathrm{~m}$ in length, $5 \mathrm{~m}$ in width and $7 \mathrm{~m}$ in depth. The pressure mapping system described below was used to record pressures induced by regular waves breaking at the face of a 1:3 sea dike constructed of concrete slabs, figure 1 . The top end of the seaward slope of the dike was located $250 \mathrm{~m}$ from the wavemaker. 4 wave gauges were used to record the surface elevation within the flume and the summary of the water depth and wave conditions is presented in table 1. A number of the waves were observed to plunge at the measuring area and whenever this condition was not fulfilled the experiment was stopped.

\begin{tabular}{|c|c|c|c|c|}
\hline $\begin{array}{l}\text { Test } \\
\text { No. }\end{array}$ & $\mathrm{H}_{\mathrm{s}}(\mathrm{m})$ & $\mathrm{T}_{\mathrm{p}}(\mathrm{sec})$ & $\begin{array}{l}\text { Water } \\
\text { depth (m) }\end{array}$ & No. of waves \\
\hline 1 & 0.6 & 4 & 4.3 & 50 \\
\hline 2 & 0.6 & 4 & 4.3 & 50 \\
\hline 3 & 0.7 & 5 & 4.3 & 30 \\
\hline 4 & 0.7 & 4 & 4.3 & 30 \\
\hline 5 & 0.6 & 3 & 4.3 & 30 \\
\hline 6 & 0.6 & 3 & 4.2 & 30 \\
\hline 7 & 0.8 & 5 & 4.6 & 30 \\
\hline 8 & 1 & 5 & 4.6 & 30 \\
\hline 9 & 0.6 & 5 & 4.6 & 30 \\
\hline 10 & 0.6 & 8 & 4.6 & Not plunging \\
\hline 11 & 0.6 & 6 & 4.6 & $<30$ \\
\hline 12 & 1 & 8 & 5 & Not plunging \\
\hline 13 & 0.8 & 4 & 4.4 & 30 \\
\hline 14 & 1 & 4 & 4.4 & 30 \\
\hline 15 & 0.8 & 3 & 4.3 & 30 \\
\hline 16 & 0.9 & 3 & 4.3 & 30 \\
\hline 17 & 1.1 & 3 & 4.3 & 30 \\
\hline 18 & 1.1 & 3 & 4.15 & 30 \\
\hline 19 & 0.9 & 3 & 4.15 & 30 \\
\hline
\end{tabular}




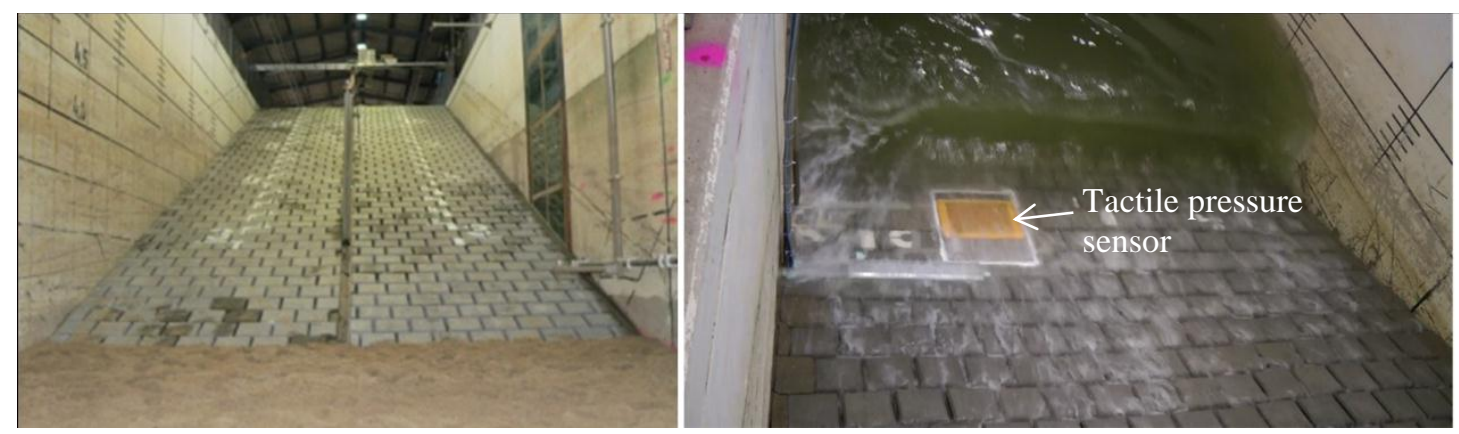

Figure 1: On left a shoreward view of the 1:3 sea dike and on the right a seaward view of a wave breaking on the sea dike. On the latter image the overall location of the pressure system is highlighted with the white paint while the location of the tactile pressure sensor is indicated by the white arrow.

\section{The pressure mapping system}

A tactile pressure sensor was used to map the impact induced pressures. Such sensors operate in a similar manner to a variable resistor of an electrical circuit. When no load is applied the resistor experiences a very high resistance, which gradually reduces as the applied load increases. Tactile pressure sensors are available in various shapes and sizes and by several manufactures. For both small and large scale experiments the sensor and system used was provided by Tekscan, Inc. For the former experiments, a sensor including 196 sensing points over an area of $7.11 \times 7.11 \mathrm{~mm}$ was used, (Stagonas et al. 2011), whilst for the latter a larger sensor was used measuring $487.7 \times 426.7 \mathrm{~mm}$ with 2016 sensing points. For all results reported here each sensing point was simultaneously sampled with $680 \mathrm{~Hz}$.

As illustrated in figure 1 the sensor was placed approximately $600 \mathrm{~mm}$ below SWL and at a horizontal distance of about $250 \mathrm{~mm}$ from the centerline. Since the sensor was only splash-proof additional waterproofing precautions were used and a vacuum was applied; as expected the vacuum introduced an initial pressure on the sensor which was removed during the post process of the results. Applied force is recorded by the sensor in binary steps ranging from 0 to 28 outputting raw values from 0 to 255; the size of the loaded area is accordingly used to convert force into pressure. Data can be displayed in the form of the time - load / pressure history over the whole sensor but also as a load / pressure map for each time step. At this point it should be noted that for all results reported in the current work only the first wave impact on the sensor was analyzed; further analysis of the data is currently taking place.

\section{Tactile sensor calibration}

Previous experience of the first author with the system has shown that the overall accuracy of the tactile pressure sensor is strongly linked to the calibration procedure used. Unfortunately for the user a calibration based on e.g. hydrostatic loads / pressures, cannot not be used when dynamic loads are applied on the sensor. Ideally the calibration procedure applied should emulate as closely as possible the nature of the dynamic event measured.

The calibration procedure used and described here was developed at FZK, Hannover specifically for these experiments. A pendulum equipped with a force transducer rated at $20 \mathrm{kN}$ was used to generate impact loads on the sensor. The upper end pendulum was mounted on a rigidly fixed plate, while its lower end was able to swing freely. A still plate covered with a sponge was fixed on the force transducer. The sensor (pressure pad) was fixed on the same rigid plate as the pendulum and the same vacuum level used for the experiments was applied. 32 different impacts were generated with the pendulum acting on a $50.58 \mathrm{~cm}^{2}$ are of the tactile sensor. Sampling frequencies for the load cell and the tactile sensor were $640 \mathrm{~Hz}$ and $2 \mathrm{kHz}$ respectively. Maximum impact forces recorded by the load cell were used to calibrate the sensor.

Figure 2 presents a schematic of the calibration arrangement, while the time-force graph comparing the measurements reported by the calibrated sensor (dashed line) and the load cell (solid line) can be seen in figure 3; for presentation reasons the sensor's signal was sifted vertically to zero. The tactile sensor is seen to overestimate force measurements by up to $12 \%$ for the smaller loads applied and by up to $5 \%$ for the higher loads applied. In addition, the time required for the sensor to return to values closer to zero appears to be about $4 \%$ higher than that of the load cell. This does necessarily directly imply a hysteresis effect for the sensor as effects introduced by e.g. the vacuum need to be considered this discussion, however, lies outside the scope of the current paper. Finally, and for all measurements reported in the following section pressures for each sensel ('sensel' is the name 
used to describe each of the 2016 measuring points of the sensor) are estimated as the ratio of the force values reported by each sensel to the area of the sensel.

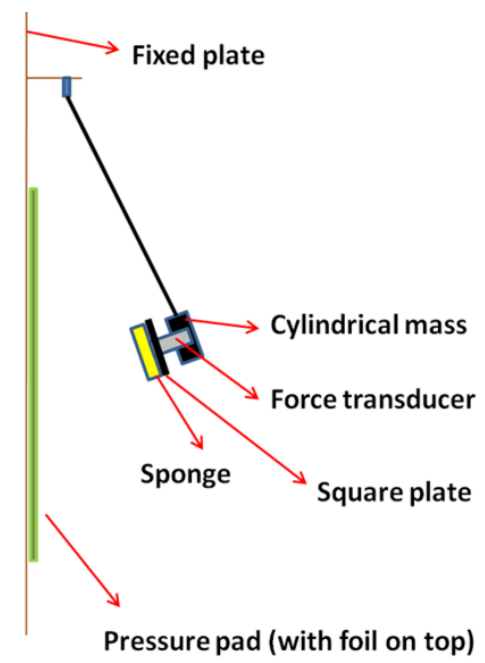

Figure 2: Schematic of the experimental arrangement developed and used for the calibration of the tactile pressure sensor

In order, however, to reassure that the response under the same load is the same for all sensels a 'normalization' procedure is required; this 'normalization' procedure is termed by the manufacturer as equilibration. For this a uniform pressure is applied on the sensor and the response of each sensel is recorded. Accordingly, a gain value is attributed to each sensel in order for its response to much the average response calculated for the whole sensor. For the current project the tactile sensor was placed within an air and water-tight arrangement (developed specifically for the equilibration of sensor and its application on the sea dike) and a vacuum pressure was generated using a vacuum pump. A similar procedure is also recommended by the sensor's manufacturer.

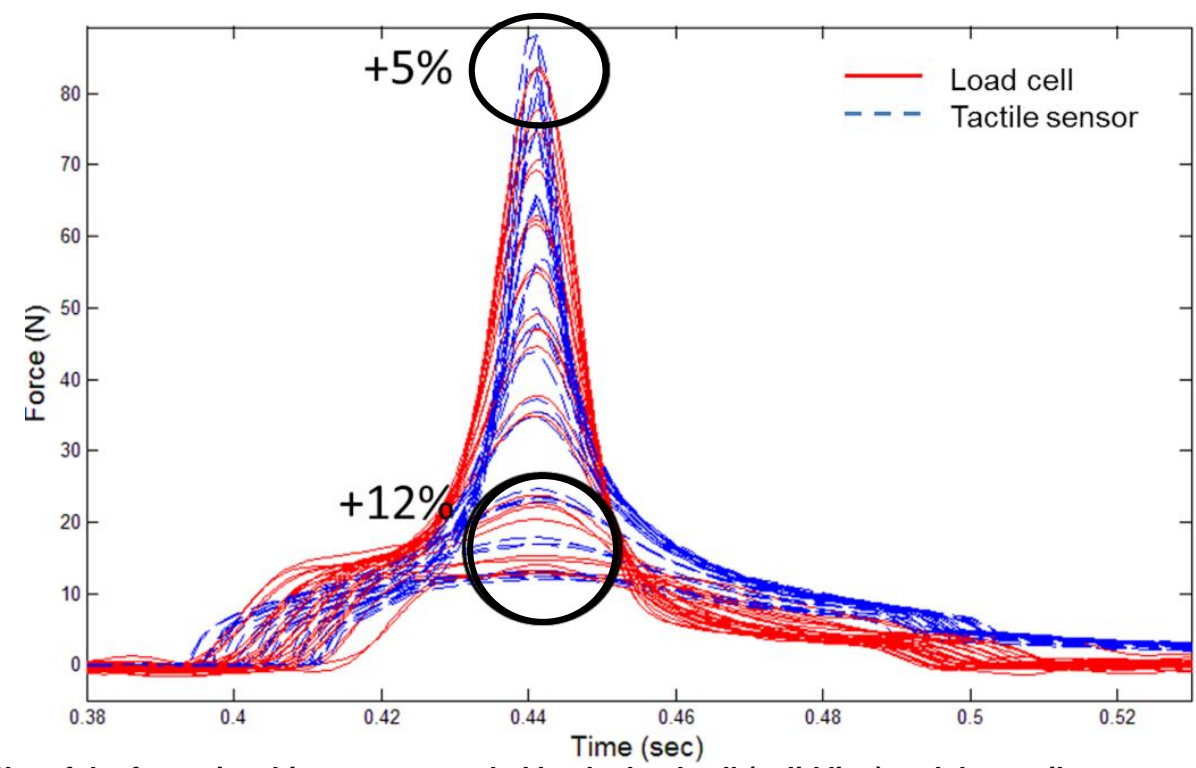

Figure 3: Plot of the force-time history as recorded by the load cell (solid line) and the tactile pressure sensor (dashed line); the latter sensor was found to overestimate the peak forces measured by $12 \%$ and $5 \%$ for the smaller and the larger applied loads, respectively. 

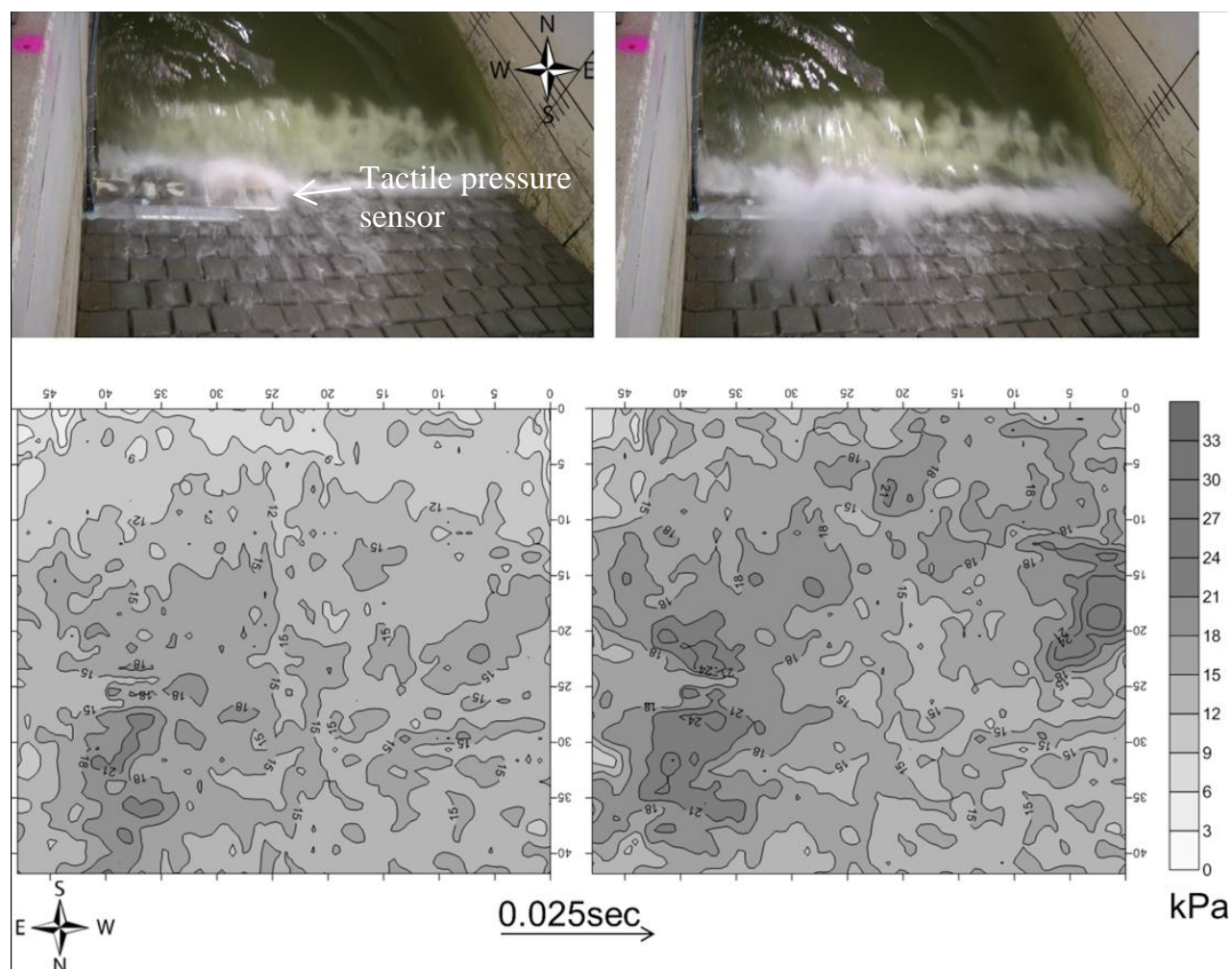

Figure 4: On the upper part snap-shots of the $0.6 \mathrm{~m}, 4 \mathrm{sec}$ wave breaking on the sea-dike. The location of the tactile sensor is also indicated. Below, the corresponding contour plots of the impact induced pressure distribution.
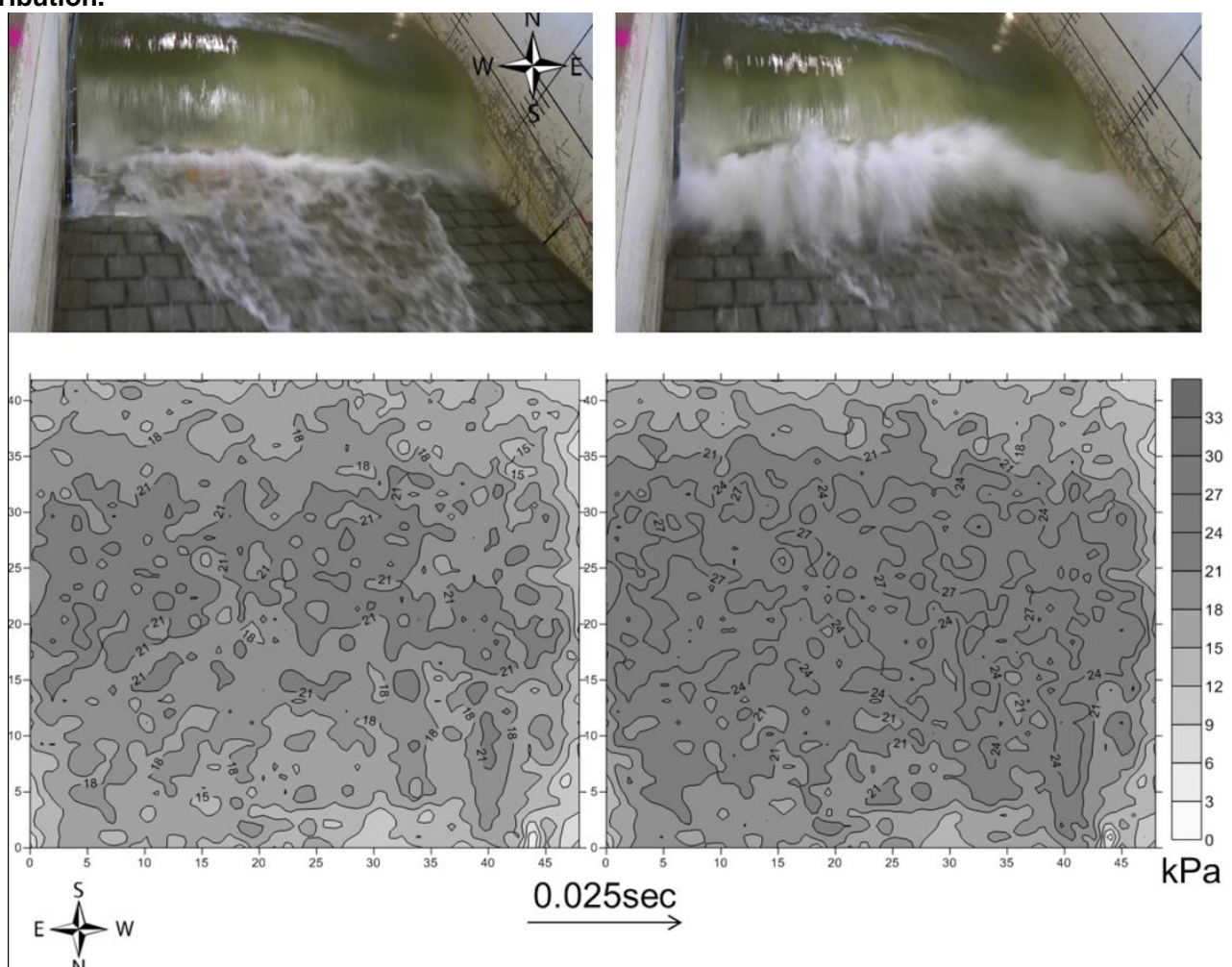

Figure 5: On the upper part snap-shots of the $0.9 \mathrm{~m}$, 3sec wave breaking on the sea-dike. The location of the tactile sensor is also indicated. Below, the corresponding contour plots of the impact induced pressure distribution. 


\section{Results}

Snap-shops of the breaking wave for the test cases No.2 and 19 are presented on the upper part of figures 4 and 5, respectively. For both figures, the wave is seen to break on the tactile sensor, the location of which is indicated. The distribution of the corresponding impact induced pressures is illustrated on the lower part of figures 4 and 5 in the form of contour plots. Moving from the left to the right of the page, the pressure magnitudes are seen to increase as the impact evolves. Pressure gradients can be distinguished within which impact pressures rise rapidly to reach the maximum value recorded for each test case (contour plot on the right hand side). In the same time, figures 4 and 5 provide preliminary evidence linking the shape of the wave during breaking to the distribution of the impact pressures. Although the existence of such a correlation between the shape of the breaking wave and the pressure distribution has been previously reported, to the author's best knowledge, this is the first time that impact pressures are mapped in such a resolution.

The vertical and horizontal location of the maximum impact pressure recorded for all test cases involving waves plunging on the tactile sensor is shown in figures 6 and 7 . At this point it should be noted that this pressure corresponds to the highest pressure value recorded by a single measuring point (sensel); the coordination system used is also included in the figures along with the direction of the incoming waves and the location of the centerline of the sea dike. In good agreement with the existing literature maximum pressures are seen to occur from $-1 * \mathrm{H}_{\mathrm{s}}$ to $-1.3 * \mathrm{H}_{\mathrm{s}}$ (- here stands for below SWL). Along the horizontal, maximum impact pressures occur at a small distance from the centerline but also at a maximum distance of about $0.77^{*} \mathrm{H}_{\mathrm{s}}$ from it. Nevertheless, those preliminary results are only indicative as they refer to the analysis of only the first impact for each test case.

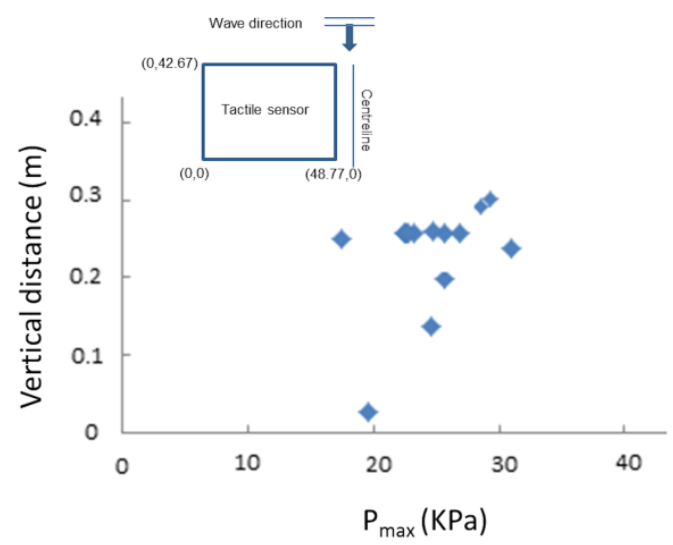

Figure 6: Plot of the vertical distribution of the maximum pressure $\left(P_{\max }\right)$ recorded for all test cases with a wave breaking over the tactile sensor. A schematic of the coordination system used is also included on the higher left part of the plot. Here, the incoming waves travel with direction from upper to the lower part of the page. Point $(0 \mathrm{~cm}, 0 \mathrm{~cm})$ is located at the lower left angle of the rectangular representing the tactile pressure sensor.

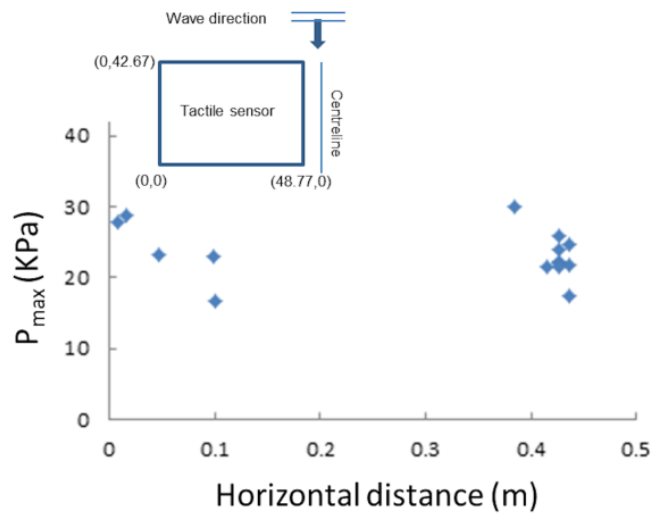

Figure 7: Plot of the horizontal distribution of the maximum pressure $\left(P_{\max }\right)$ recorded for all test cases with a wave breaking over the tactile sensor. A schematic of the coordination system used is also included on the higher left part of the plot. Here, the incoming waves travel with direction from upper to the lower part of the page. Point $(0 \mathrm{~cm}, 0 \mathrm{~cm})$ is located at the lower left angle of the rectangular representing the tactile pressure sensor. 


\section{Conclusions}

- A method to calibrate and use tactile pressure sensors with large scale breaking waves has been described here. The comparison between the results acquired from a tactile pressure sensor and a load cell mounded on a pendulum impacting on the tactile sensor revealed a decreased accuracy for the latter instrument. As such tactile sensors should not be e.g. considered an alternative to pressure transducers. However, even with lower accuracy levels, they have the potential to provide spatial information at a very high resolution and they can be used even for large scale experiments involving breaking waves.

- Contour plots of impact induced pressures indicate the development of areas with sharp pressure gradients under the breaking wave. The comparison of figures 4 and 5 seems also to suggest a correlation between the distribution of the impact pressures and the shape of the wave at breaking.

- The location of maximum pressures along the vertical and the horizontal was deduced from high resolution pressure maps. Preliminary findings for the vertical location $\left(-1 * \mathrm{H}_{s}\right.$ to $-1.3 * \mathrm{H}_{\mathrm{s}}$ ) of maximum pressures agreed with the existing literature. In the same time, maximum pressures were also located at a horizontal distance of up to about $0.77 * \mathrm{H}_{\mathrm{s}}$ from the centerline of the sea dike.

Overall, results presented here form only evidence and further research and analysis is required before more solid conclusions can be drawn.

\section{ACKNOWLEDGMENTS}

The authors wish to acknowledge the financial support by the European Community's 7th Framework Programme through the grant to the budget of the Integrating Activity HYDRALAB IV, Contract no. 261520.

\section{REFERENCES}

Burcharth, H.F. and Hughes, S.A., 2005. Chapter 2: Types and Functions of Coastal Structures, EM 1110-2 1100, Part VI, 28 February 2005.

Davidse, M.P., 2009. Wave impact on asphaltic concrete revetments, MSc thesis, Delft University of Technology.

Fuhrboter, A. and Sparboom, U., 1988. Full-scale wave attack of uniformly sloping sea dykes, Proceedings 21st International Conference on Coastal Engineering, ASCE, 2174-2188.

Grune, J. 1988. Wave induced shock pressures under real state conditions, Proceedings 21st International Conference on Coastal Engineering, ASCE, 2340-2354.

Grune, J. 1992. Loads on sloping seadykes and revetments from wave-induced

Klein Breteler, M., 2007. Validatie van GOLFKLAP (Report H4134) (in Dutch), WL/Delft Hydraulics. Important findings also reported in Davidse (2009)

Marth, R., Nehrig, M., Muller, G. and Wolters, G., 2005. Wave impact induced internal pressures in blockwork coastal structures. Available at: ftp://ftp.hamburg.baw.de/pub/Kfki/Bib/2005 iceland symposium/Data/B5.2/marth PA.pdf, on 7/7/2011.

Recio, J. and Oumeraci, H., 2009. Processes affecting the hydraulic stability of coastal revetments made of GSC. Coastal Engineering, Elsevier, Vol. 6, No. 3, pp. 260-284.

Shock pressures. Proceedings 23rd International Conference on Coastal Engineering, ASCE, 11751188.

Stagonas, D. Muller, G. Batten W. and D. Magagna, 2011. Mapping the temporal and spatial distribution of experimental induced pressures at vertical seawalls: a novel method. 5th SCACR, Aachen, Germany.

Stanczak, G., 2008. Breaching of sea dikes initiated from the seaside by breaking wave impacts, $\mathrm{PhD}$ Thesis, University of Braunschweig and University of Florence.

TAW., 1984. Leidraad voor toepassing van asfalt in de waterbouw (in Dutch), Staatsuitgeverij, 's Gravenhage. Important findings also reported in Davidse (2009) 